\title{
Basil oil incorporated beeswax coating to increase shelf life and reduce anthracnose development in mango cv. Willard
}

K.O.L.C. Karunanayake*, K.C.M. Liyanage, L.K.R.R. Jayakody and S. Somaratne

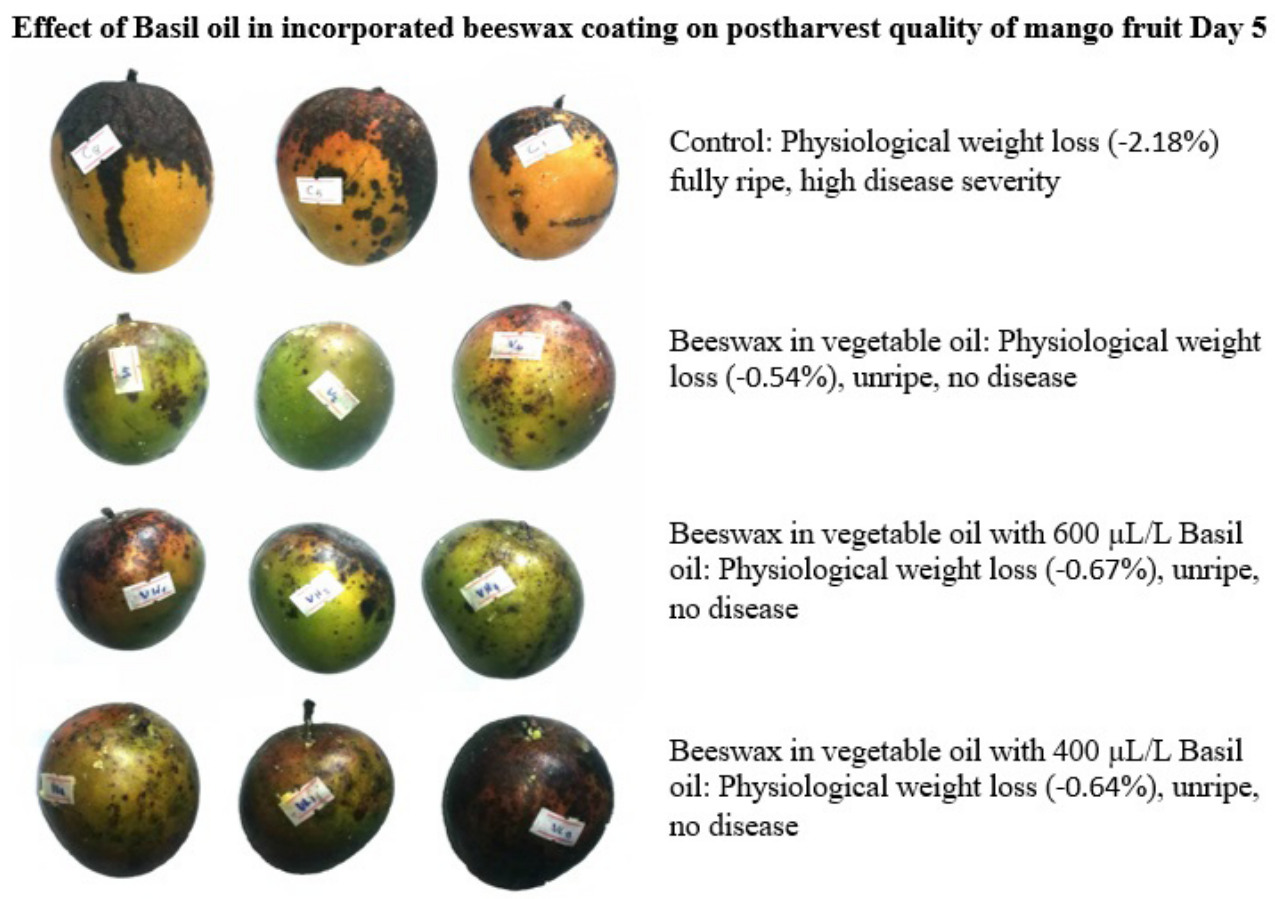

\section{Highlights}

- Melted beeswax in vegetable oil or pet ether can be applied to fruits as a coating to significantly reduce $\%$ weight loss and significantly increase the number of days taken to reach table ripe maturity in fruits of $\mathrm{cv}$. 'Willard'

- Melted beeswax in vegetable oil (1:3 w/v) with $600 \mu \mathrm{L} \mathrm{L}^{-1}$ basil oil significantly reduces anthracnose development in mango fruits of cv. 'Willard'

- Melted beeswax in vegetable oil $(1: 3 \mathrm{w} / \mathrm{v})$ with $600 \mu \mathrm{L} \mathrm{L}^{-1}$ basil oil is preferred by taste panelist over the pet ether solvent. 
RESEARCH ARTICLE

\title{
Basil oil incorporated beeswax coating to increase shelf life and reduce anthracnose develop- ment in mango cv. Willard
}

\author{
K.O.L.C. Karunanayake*, K.C.M. Liyanage, L.K.R.R. Jayakody and S. Somaratne \\ Department of Botany, Faculty of Natural Sciences, The Open University of Sri Lanka, Nawala, Nugegoda, Sri Lanka
}

Received: 28/02/2020; Accepted: 06/10/2020

\begin{abstract}
Use of biologically safe, essential oil-incorporated fruit coatings to reduce postharvest losses has become an attractive alternative to synthetic fungicides in recent years. Increase in shelf life due to reduced water loss and reduced evaporation of essential oils (EO) within the coating are key advantages of incorporating EOs to fruit coatings. The effect of beeswax as a fruit coating with and without essential oil on the postharvest quality and natural disease development of mango (cv. Willard) was evaluated by conducting a laboratory experiment. Pure Beeswax, dissolved either in vegetable oil $(1: 3 \mathrm{w} / \mathrm{v})$ or petroleum ether $(1: 4 \mathrm{w} / \mathrm{v})$, served as the coating material. Basil oil at 400 or $600 \mu \mathrm{L} \mathrm{L}^{-1}$ was incorporated to the different coating material. Fruits with no coating and no essential oil served as controls. Eight replicate fruits were used per treatment and three trials were performed. Treated fruits were arranged in a Completely Randomized Design and kept under ambient conditions. Daily observations were made on natural disease development and weight loss. The Total Soluble Solid content and titrable acidity were measured at eating ripe stage and sensory evaluation by a taste panel was also obtained. Data were analyzed using ANOVA with SPSS software version 20.0 package. Results indicated that basil oil in beeswax significantly reduced physiological weight loss, delayed fruit ripening and also delayed and reduced postharvest disease development.
\end{abstract}

Keywords: Basil oil, anthracnose, mango, fruit coating, beeswax.

\section{INTRODUCTION}

Due to increasing awareness of the benefits of a balanced diet and healthy eating habits, there is a high consumer demand for fresh fruits and vegetables. Although the production of fresh commodities is high, a large percentage of fresh produce is lost postharvest, due to diseases caused by microorganisms. Except for the 'organic' food products, the remainder are highly polluted with chemical fungicides. Application of synthetic chemicals for prevention of postharvest diseases is at present being misused. The use of essential oils (EO) for the control of disease has become an attractive alternative to synthetic chemicals due to its therapeutic activity and toxicity to fungi, bacteria and insects (Delespaul et al., 2000). The oils of herbs such as thyme (Thymus), marjoram (Origanum) and basil (Ocimum) are generally regarded as safe (GRAS) and contain compounds such us cinnamaldehyde, acetaldehyde and eugenol. Use of essential oils for the control of postharvest diseases has been tried out with promising results on fruits such as mandarin, kiwi and rambutan (Arras, 1988; Thanassoulopoulos and Yanna, 1997; Sivakumar et al., 2002).

Anthracnose of mango has been effectively controlled by the use of essential oils, ginger and cinnamon (Sefu et al., 2015), lemongrass (Duamkhanmane, 2008), basil oil (Ocimum basillicum), orange oil (Citrus sinensis), lemon oil (Citrus medica) and mustard oil (Brassica juncea) (Abd-alla and Haggag, 2013). In Sri Lanka, extensive work has been carried out by Abeywickrama and coworkers (Abeywickrama et al., 2003; Anthony et al., 2004; Anthony et al., 2003) on the use of essential oils for the control of postharvest diseases of banana fruit. Treatment with oil of Ocimum basilicum controlled crown rot and anthracnose of banana with no detrimental effect on organoleptic properties (Anthony et al., 2004) while Cymbopogon nardus and $O$. basilicum oils were directly fungitoxic to common postharvest pathogens in banana, Colletotrichum musae, Lasiodiplodia theobromae and Fusarium proliferatum (Anthony et al., 2004). Cardamom oil in warm water $\left(45^{\circ} \mathrm{C}\right)$, used as a dip treatment in vivo, significantly reduced Stem-end rot development in mango cv 'Karuthacolomban' (Kulasinghe et al., 2019) and spray and fumigation treatments with basil, clove, cinnamon leaf and cinnamon bark oils effectively controlled SER in mango cv 'Karthacolomban' stored at $12-14{ }^{\circ} \mathrm{C}$ (Kodituwakku et al., 2020).

However, due to their high volatile nature, the essential oils are more effective when they are incorporated into a coating material and then applied to a fruit. Edible coatings, which slowdown the ripening process, protect the fruit from water loss and spoilage, may be a good way to increase the shelf life of fresh produce (Antunesa et al., 2012). More recently, the inclusion of additives such as essential oils and other constituents with antimicrobial or antioxidant properties, into edible coatings to enhance their effectiveness, has been reported and patented (Antunesa et al., 2012). Cinnamon oil incorporated to beeswax (BW) has been found to reduce microbial contaminations and increase shelf life of sweet peppers (Yimtoe et al., 2014). BW and chitosan as fruit coatings, at different concentrations $(0.5 \%, 1.5 \%$ and $2 \%)$, were applied on 
two mango varieties 'Apple' and 'Tommy Atkins' (Eshetu et al., 2018). Application of beeswax and chitosan at $2 \%$, significantly reduced physiological weight loss, disease incidence, maintained firmness and prolonged shelf life of fruits compared with untreated control (Eshetu et al., 2018).

The present research was conducted to investigate the effect of basil oil-enriched beeswax coating material in controlling anthracnose disease caused by Colletotrichum spp. and also evaluate its effect on ripening and physicochemical, organoleptic parameters of the fruit. Anthracnose is one of the most important and widely distributed diseases of mango cv. Willard (Karunanayake et al., 2013).

\section{MATERIALS AND METHODS}

\section{Essential oil}

Pure-grade essential oil of basil (Ocimum basilicum) was obtained from Herbal Exotics, Pugoda, Sri Lanka.

\section{Fruits}

Mature, unblemish-free mango fruits of cv. 'Willard' at harvesting maturity were obtained from Anuradhapura $\left(8.3114^{\circ} \mathrm{N}, 80.4037^{\circ} \mathrm{E}\right.$ ) (North Central Province) within 24 $\mathrm{h}$ of harvest. The fruits were transported to the Department of Botany Research Laboratory in The Open University of Sri Lanka, washed in tap water and allowed to dry under ambient conditions. Healthy, unripe fruits of uniform maturity were used in experiments.

\section{Preparation of bio-safe coatings}

Beeswax (Beeswax pure for histology, 24031-02473688012-89-3, SRL) was melted at $65{ }^{\circ} \mathrm{C}$ in a water bath as double boiled. Beeswax (BW) in vegetable oil $(1: 3 \mathrm{w} / \mathrm{v})$ and $\mathrm{BW}$ in pet ether $(1: 4 \mathrm{w} / \mathrm{v})$ were prepared with slight modifications to the method described by Mladenoska (2012).

\section{Preparation of essential oil mix with coating}

Basil oil and the suitable concentration were selected based on preliminary trials by Kulasinghe (2016). Although a higher concentration of the EO was necessary to retard the growth of $C$. gloeosporioides in vitro, a lower concentration $\left(600 \mu \mathrm{L} \mathrm{L}^{-1}\right)$ of EO was sufficient to retard disease development when incorporated as an emulsion with a coating material as identified in preliminary trials. One litre of each coating material was prepared by mixing coating material and essential oil as follows: BW with pet ether 1:4 without basil oil, BW with pet ether 1:4 +600 $\mu \mathrm{L} \mathrm{L}^{-1}$ basil oil, BW with pet ether $1: 4+400 \mu \mathrm{L} \mathrm{L}^{-1}$ basil oil, BW with vegetable oil 1:3 without basil oil, BW with vegetable oil 1:3+600 $\mu \mathrm{L} \mathrm{L}^{-1}$ basil oil, BW with vegetable oil 1:3+400 $\mu \mathrm{L} \mathrm{L}^{-1}$ basil oil and untreated control dipped in distilled water alone.

\section{Effect of the in vivo essential oil treatments on physiological weight loss (\%)}

Weight loss was determined by weighing of fruits daily for 5 days using a digital balance (Radwag, PS6000.R2). The average weight of all fruits in each treatment was taken and at the end of the experiment \% weight loss was calculated by the formula of Gerefa et al. (2015),

Physiological weight loss

$=\underline{\text { Initial weight of fruits- Final weight of fruits }} \times 100$

Initial weight of fruits

\section{Effect of in vivo treatment on disease incidence and severity}

The number of fruits showing any visual sign of disease out of the eight replicates was recorded on a daily basis. The number of fruits with symptoms of disease served as the disease incidence and this was presented as a percentage. Anthracnose severity was determined visually for each fruit subjected to different treatments based on the digital image scale (Corkidi et al., 2006). The disease severity was recorded daily as a percentage and the average value was determined per day per treatment.

\section{Effect of treatments on physicochemical properties}

Pulp pH

Four (4) fruits of mango, at table ripe stage, were selected from each treatment and fruit pulp was made into juice without adding water. Pulp $\mathrm{pH}$ was measured using a calibrated digital $\mathrm{pH}$ meter (IQ150 Spectrum Technologies Inc.).

\section{Flesh firmness}

Flesh firmness was determined in mango fruit (4 replicate fruits) at table ripe stage using a hand-held penetrometer (Model FT 40 Wagner instruments Greenwich CT).

\section{Total Soluble Solids ( ${ }^{\circ}$ Brix)}

To determine the total soluble solids content (TSS), four mango fruits at table ripe stage from each treatment were selected and fruit pulp was made into juice without adding water. The Brix value of the pulp of each treatment was recorded using a portable refractometer (WZ113- Zhejiang top instruments Co Ltd, Brix/ATC $0 \sim 32 \%$ ) of 0-32 Brix range at $\mathrm{RT}\left(25 \pm 2{ }^{\circ} \mathrm{C}\right)$ and expressed as ${ }^{\circ} \mathrm{Brix}$ (Samane $e t$ al., 2012).

\section{Effect of treatments on fruit ripening}

Mango fruits cv. 'Willard', which changed their peel colour from green-red to yellow-red, were considered to have reached table ripe stage of maturity. The number of fruits that have undergone the desired colour change were noted daily from day 1 to 5 after treatment. The average number of ripe fruits per day for each treatment was recorded.

\section{Effect of treatments on sensory properties - Taste panel}

A panel of untrained 27 adults (aged above 21 years), comprising both male and female, was randomly selected for sensory evaluation. A five-point hedonic scale, described by Larmond (1977) was used where $5=$ very high, $4=$ high, $3=$ moderate, $2=$ low and $1=$ very low. The samples were served in identical plates. The organoleptic properties of interest were: color (both peel and flesh color), appearance, 
texture, odor and taste (Umuhozariho et al., 2013).

\section{Statistical analysis}

Eight replicate fruits were used per treatment and all experiments were performed thrice. Both treated and control fruits were arranged in a completely randomized design (CRD) and kept on laboratory tables in clean plastic trays under ambient conditions for 5 days after treatment. Data were analyzed as a factorial ANOVA using the statistical package, IBM SPSS version 20.0. After applying the Least Significant Difference (LSD) test, differences of $P \leq 0.05$ were considered as significant. For sensory evaluation data, Principal Component Analysis (PCA) and cluster analysis were used to identify the preferences of the panelists for the samples.

\section{RESULTS AND DISCUSSION}

\section{Physiological weight loss}

Physiological weight loss was determined in treated and control fruits from day 1 to day 5 after treatment. The physiological weight loss was significantly higher in the control fruits which had no coating material or EO treatment on all days considered as opposed to the fruits receiving treatments (Figure 1). Physiological weight loss among treatments (except the control) were not significantly different (Figure 1). Either BW coating in pet ether or vegetable oil or the same coatings incorporated with $\mathrm{EO}$ had significantly lesser weight loss when compared with the control. Mladenoska (2012), Foo (2019) and Yimtoe et al. (2014) also reported that beeswax when applied as a fruit coating significantly reduced the weight loss of fruits.
The disease incidence and severity were determined in controls and fruits treated with essential oil incorporated coating material from day 1 to 5 after treatment. Anthracnose symptoms were visible in fruits following 3 days of incubation (Table 1a).

The highest disease incidence and severity were seen in control fruits, on days 4 and 5, this was followed by fruits which received only the coating treatment, either beeswax in vegetable oil or beeswax in pet ether; the fruits which received basil oil incorporated coating had the lowest disease incidence and severity (Table 1a, b). Of the two basil oil treatments, the lowest disease incidence and severity were seen in the higher $\left(600 \mu \mathrm{L} \mathrm{L}^{-1}\right)$ basil oil treatment. Control fruits had significantly higher disease severity compared to all other treated fruits. By the day 5 , an average of $50 \%$ disease severity was observed in the control fruits whereas all treated fruits had less than $10 \%$ disease severity (Table 1b). Similarly, Yimtoe et al. (2014) reported that application of cinnamon oil incorporated beeswax on sweet peppers reduced microbial development and also reduced weight loss when compared with uncoated controls.

The lowered disease incidence and severity in fruits that received basil oil incorporated coating, could be due to the antimicrobial activity found in several components of basil oil. The antimicrobial activity of basil against various microbes has been reported in previous studies (Bozin et al., 2006; Sokovic and Griensven, 2006) and many scientists have linked the antimicrobial effects of basil to the higher level of linalool which is the main component of the oil (Juliani and Simon, 2002).

\section{Physicochemical properties}

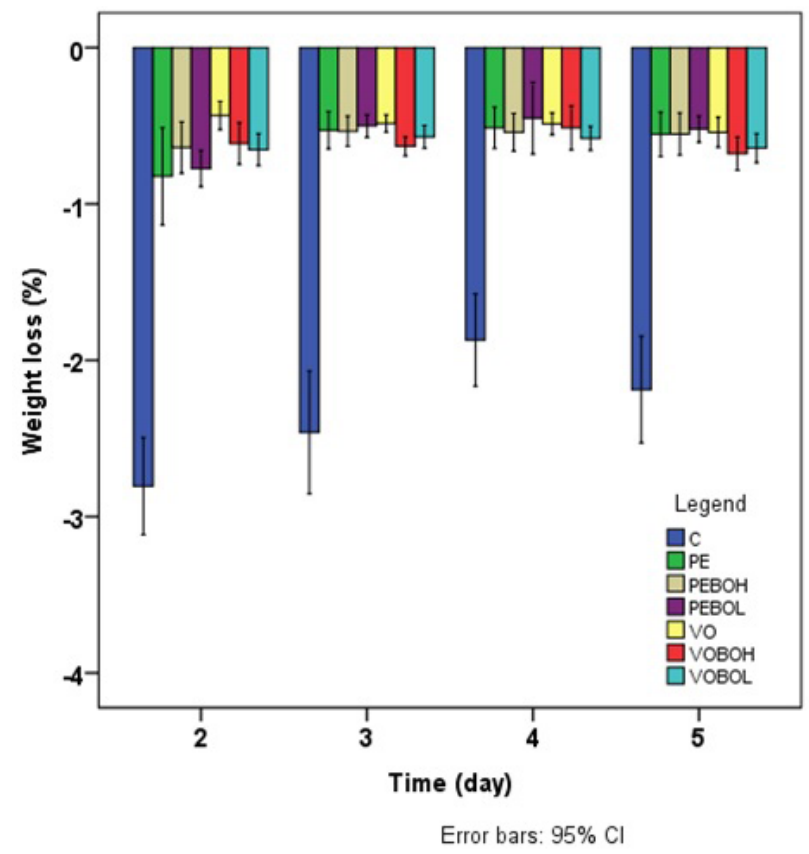

Figure 1: Physiological weight loss (\%) in control fruits and fruits coated with varying beeswax coatings from day 1 to 5 after treatment, C- control, PE- beeswax dissolved in Pet ether, PEBOH- beeswax in pet ether with $600 \mu \mathrm{L} \mathrm{L}^{-1}$ basil oil, PEBOL- beeswax in pet ether with $400 \mu \mathrm{L} \mathrm{L}^{-1}$ basil oil, VO- beeswax dissolved in vegetable oil, VOBOH- beeswax in vegetable oil with $600 \mu \mathrm{L} \mathrm{L}^{-1}$ basil oil, VOBOL- beeswax in vegetable oil with $400 \mu \mathrm{L} \mathrm{L}^{-1}$ basil oil. Error bars at $95 \%$ confidence interval. 
Table 1: Average number of fruits showing disease symptoms expressed as a \% (a), and the severity of the disease \% (b), in the control fruits and fruits coated with beeswax either with or without EO.

(a) Disease incidence

\begin{tabular}{lrrr}
\hline \multirow{2}{*}{$\begin{array}{l}\text { Treatment } \\
\text { code }\end{array}$} & \multicolumn{3}{c}{ Disease incidence (\%) } \\
\cline { 2 - 4 } & \multicolumn{1}{c}{ Day 3 } & Day 4 & \multicolumn{1}{c}{ Day 5 } \\
\hline *Control & 50 & 75 & 75 \\
PE & 50 & 50 & 50 \\
PEBOH & 25 & 37.5 & 37.5 \\
PEBOL & 37.5 & 37.5 & 50 \\
VO & 50 & 50 & 50 \\
VOBOH & 37.5 & 37.5 & 37.5 \\
VOBOL & 62.5 & 62.5 & 62.5 \\
\hline
\end{tabular}

(b) Disease severity

\begin{tabular}{lllll}
\hline \multirow{2}{*}{$\begin{array}{l}\text { Treatment } \\
\text { code }\end{array}$} & \multicolumn{2}{l}{ Disease severity (\%) } & status of disease \\
\cline { 2 - 4 } & Deverity 3 & Day 4 & Day 5 & \\
\cline { 2 - 4 } $\mathrm{C}$ & $6-9$ & $10-49$ & $10-49$ & Severe \\
PE & $1-5$ & $6-9$ & $6-9$ & Moderate \\
PEBOH & $0-1$ & $0-1$ & $0-1$ & No disease \\
PEBOL & $0-1$ & $0-1$ & $1-5$ & Slight \\
VO & $0-1$ & $1-5$ & $1-5$ & Slight \\
VOBOH & $0-1$ & $0-1$ & $0-1$ & No disease \\
VOBOL & $0-1$ & $0-1$ & $0-1$ & No disease \\
\hline
\end{tabular}

${ }^{*} \mathrm{C}$ - control, PE- beeswax dissolved in Pet ether, PEBOH- beeswax in pet ether with $600 \mu \mathrm{L} \mathrm{L}^{-1}$ basil oil, PEBOL- beeswax in pet ether with $400 \mu \mathrm{L} \mathrm{L}^{-1}$ basil oil, VO - beeswax dissolved in vegetable oil, VOBOH- beeswax in vegetable oil with $600 \mu \mathrm{L} \mathrm{L}^{-1}$ basil oil, VOBOL- beeswax in vegetable oil with $400 \mu \mathrm{L} \mathrm{L}^{-1}$ basil oil.

\section{Pulp pH, flesh firmness and total soluble solids content}

Ripe mango has a slightly acidic $\mathrm{pH}$ value range of 5.8-6.0. $\mathrm{pH}$ value in all treated and control fruits was within this range. Islam et al. (2013) also reported similar values for pulp $\mathrm{pH}$ in mango fruit. There was no significant difference in pulp $\mathrm{pH}$ between treated and control fruits (Table 2). Therefore, the coating material and the EO treatment did not affect the $\mathrm{pH}$ of fruits. Flesh firmness was not affected by treatments (Table 2). All treated and control fruits had flesh firmness ranging from 1.48 to 1.8 and there was no significant difference between treatments.

Total soluble solids in all treated and control fruits were in an acceptable range at table ripe stage. Control fruits had the highest TSS compared to the others (Table 2). The TSS, in fruits receiving different treatments, was not significantly different, however, the TSS in control fruits was significantly higher. Foo et al. (2019) also reported a lower breakdown in soluble solids in beeswax coated fruits. Since all treated fruits received a beeswax coating, this could be the reason for the lower TSS. Brix value for sugar content is given as $4 \%$ for poor, $6 \%$ for average, $10 \%$ for good and $14 \%$ for excellent in mango fruit (Harrill, 1998). The control fruits accordingly can receive excellent grading. However, all treated fruits are also in the 'good' category. Abeywickrama et al. (2009) also reported that no significant effects on physicochemical parameters, titrable acidity, $\mathrm{pH}$, TSS and pulp firmness were visible in banana fruit treated with basil oil.

\section{Effect of treatments on ripening}

The number of days taken to reach table-ripe stage of maturity increased significantly in treated fruits receiving beeswax coating alone or with EO when compared with control fruits. Ripening commenced after 3 days in control fruits $(37 \%)$ while ripening was seen to commence only 4 days after treatment in the fruits which received coating treatments (Table 3). By the day 5, 100\% of control fruits were ripe while only $25 \%$ of treated fruits were in ripe stage. Foo et al. (2019) also report that senescence, weight loss and breakdown of soluble solids in the fruit were slowed down by beeswax coatings. Yimtoe et al. (2014) reported that cinnamon oil incorporated beeswax coatings increased shelf life while maintaining quality of sweet pepper under ambient and cold storage conditions. Generally, edible coatings are known to create a modified atmosphere and reduce weight loss, metabolic activities and protect the commodity from microbial attack during transport and storage (Tripathi and Dubey, 2004).

\section{Effect of the treatments on sensory properties - Taste Panel}

According to the results of the taste panel, the control (No wax, no oil) fruits were the most preferred (Figure 2) and the second most acceptable were the fruits coated with beeswax in vegetable oil with $600 \mu \mathrm{L} \mathrm{L}^{-1}$ basil oil (Figure 2). All the other treatments were not rated favourably by the panelists. Abeywickrama et al. (2009) also report that in banana treated with basil oil the most preferred by the panelists was the control.

\section{CONCLUSIONS}

Beeswax treatment significantly reduces weight loss, disease incidence, disease severity and significantly increases the number of days taken to reach table ripe stage of maturity in mango fruits of cv. 'Willard'. Incorporating basil oil at $600 \mu \mathrm{L} \mathrm{L}^{-1}$ to beeswax coating was the most effective to control anthracnose and $600 \mu \mathrm{L} \mathrm{L}^{-1}$ beeswax in vegetable oil was also the most preferred by the taste panelists second only to the control. However, the method used to dissolve the beeswax needs to be considered. The pet ether solvent was not favourable to taste panelists while the vegetable oil solvent was preferred. The physicochemical properties except TSS were not affected by the treatment, however, there appears to be a slight effect on the organoleptic properties of the fruit as the control was the most preferred by the taste panelists. 
Table 2: Physicochemical parameters in the control fruits and fruits coated with beeswax, with or without EO treatment at table ripe stage of maturity. Table gives, mean value +or- standard deviation

\begin{tabular}{llll}
\hline Physicochemical parameter & & & \\
\hline Treatment Code & $\mathrm{pH}$ & Firmness & $\mathrm{TSS}$ \\
\hline Control & $5.04 \pm 0.08$ & $1.39 \pm 0.11$ & $12.86 \pm 0.96$ \\
Beeswax in pet ether & $4.80 \pm 0.20$ & $1.85 \pm 0.25$ & $11.00 \pm 1.00$ \\
Beeswax in pet ether $600 \mu \mathrm{L} \mathrm{L}^{-1}$ basil oil & $4.75 \pm 0.05$ & $1.60 \pm 0.20$ & $11.00 \pm 3.00$ \\
Beeswax in pet ether $400 \mu \mathrm{L} \mathrm{L}^{-1}$ basil oil & $4.85 \pm 0.05$ & $1.45 \pm 0.85$ & $11.00 \pm 1.00$ \\
Beeswax in veg oil & $4.90 \pm 0.00$ & $1.90 \pm 0.00$ & $8.00 \pm 0.00$ \\
Beeswax in veg oil $600 \mu \mathrm{L} \mathrm{L}^{-1}$ basil oil & $4.70 \pm 0.00$ & $1.90 \pm 0.00$ & $11.00 \pm 0.00$ \\
Beeswax in veg oil $400 \mu \mathrm{L} \mathrm{L}^{-1}$ basil oil & $4.60 \pm 0.00$ & $1.80 \pm 0.00$ & $10.00 \pm 0.00$ \\
\hline
\end{tabular}

Table 3: The percentage (\%) of fruits to reach table ripe stage of maturity from days 3 to 5 after treatment

\begin{tabular}{llll}
\hline Treatment Code & D ay 3 \% & Day 4 \% & Day 5 \% \\
\hline Control & 37.50 & 62.50 & 100 \\
Beeswax in pet ether & 0 & 25 & 25 \\
Beeswax in pet ether $600 \mu \mathrm{L} \mathrm{L}^{-1}$ basil oil & 0 & 25 & 25 \\
Beeswax in pet ether $400 \mu \mathrm{L} \mathrm{L}^{-1}$ basil oil & 0 & 25 & 25 \\
Beeswax in veg oil & 0 & 12.50 & 12.50 \\
Beeswax in veg oil $600 \mu \mathrm{L} / \mathrm{L}$ basil oil & 0 & 25 & 25 \\
Beeswax in veg oil $400 \mu \mathrm{L} / \mathrm{L}$ basil oil & 0 & 25 & 25 \\
\hline
\end{tabular}

Figure 2: Radar plot representation of the taste panel results.: Control- no coating or EO, PE - Bees wax in Pet ether, PEBOh- Bees wax in Pet ether: $600 \mu \mathrm{L} \mathrm{L}^{-1}$ Basil oil, PEBOl - Bees wax in Pet ether: $400 \mu \mathrm{L} \mathrm{L}^{-1}$ Basil oil, VO - Bees wax in Vegetable oil, VOBOh - Bees wax in Vegetable oil: $600 \mu \mathrm{L} \mathrm{L}^{-1}$ Basil oil, VOBOl- Bees wax in Vegetable oil: $400 \mu \mathrm{L} \mathrm{L}^{-1}$ Basil oil.

\section{Taste Panel}

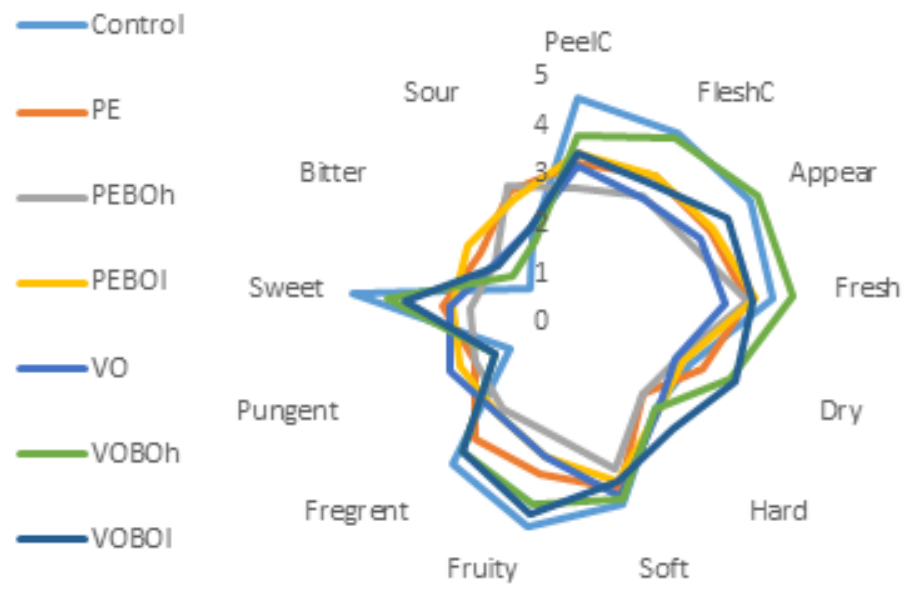




\section{ACKNOWLEDGEMENTS}

This research was supported by funds received through the Faculty research grant, Faculty of Natural Sciences, OUSL 2017-18.

\section{DECLARATION OF CONFLICT OF INTEREST}

The authors declare no conflict of interest.

\section{REFERENCES}

Abd-alla, M.A. and Haggag, W.M. (2013). Use of some essential oils as postharvest botanical fungicides in the management of anthracnose disease of mango fruits caused by Colletotrichum gloeosporioides. International Journal of Agriculture and Forestry 3(1): $1-6$.

Abeywickrama, K., Anthony, S. and Watawala, R. (2003). Fumigant action of selected essential oils against banana fruit pathogens. Journal of the National Science Foundation of Sri Lanka 31(3-4): 427-429. http://doi. org/10.4038/jnsfsr.v31i3-4.2469

Abeywickrama, K., Wijerathna, C., Herath, H. and Sarananada, K.H. (2009). An integrated treatment of basil oil (Ocimum basilicum) and alum with modified atmosphere to control crown rot disease in 'embul' banana. Tropical Agricultural Research \& Extension 12(1): 23-30.

Adriana, C. G., Custódia, M.L.G., Maria, L.F., Maria, G.C.M. and Antunes, M.D.C. (2015). The effect of alginate-based edible coatings enriched with essential oils constituents on Arbutus unedo L. fresh fruit storage. Postharvest Biology and Technology 100: 226-233.

Anthony, S., Abeywickrama, K. and S.W. Wijeratnam (2003). The effect of spraying essential oils of Cymbopogon nardus, Cymbopogon flexuosus and Ocimum basilicum on postharvest diseases and storage life of 'Embul' banana. The Journal of Horticultural Science and Biotechnology 78(6): 780-785

Anthony, S., Abeywickrama, K., Dayananda, R., Wijeratnam, S.W. and Arambewela, L. (2004). Fungal pathogens associated with banana fruit in Sri Lanka and their treatment with essential oils. Mycopathologia 157(1): 91-97.

Antunesa, M.D., Gagoa, C.M., Cavacob, A.M. and Miguela, M.G. (2012). Edible coatings enriched with essential oils and their compounds for fresh and fresh-cut fruit. Recent Patents on Food, Nutrition \& Agriculture 4: 114-122.

Arras, G. (1988). Antimicrobial activity of various essential oils and their isolates for blue mold decay control in Citrus reticulata. Journal of Food Science and Technology 14: 14-16.

Bill, M., Sivakumar, D., Korstein, L. and Thompson, K.A. (2014). The efficacy of combined application of edible coatings and thyme oil in inducing resistance components in avocado (Persea americana Mill.) against anthracnose during postharvest storage. Crop Protection 64: 1-9.

Bogdanov, S. (2004). Beeswax: quality issues today. Bee World 85(3): 46-50.

Bozin, B., Mimica-Dukie, N., Simin, N. and Anackov, G.
(2006). Characterization of the volatile composition of essential oils of some Lamiaceae spices and the antimicrobial and antioxidant activities of entire oils. Journal of Agricultural and Food Chemistry 54: 18221828.

Corkidi, G., Balderas-Ruíz, K.A., Taboada, B., Serranocarreon, L. and Galindo, E. (2006). Assessing mango anthracnose using a new three-dimensional imageanalysis technique to quantify lesions on fruit. Plant Pathology 55(2): 250-257.

Delespaul, Q., de Billerbeck, V.G., Roques, C.G., Michel, G., Marquier-Viñuales, C. and Bessière, J.M. (2000). The antifungal activity of essential oils as determined by different screening methods. Journal of Essential Oil Research 12: 256-266.

Duamkhanmanee, R. (2008). Natural essential oils from lemon grass (Cymbopogon citratus) to control postharvest anthracnose of mango fruit. International Journal of Biotechnology 1: 104-108.

Eshetu, A., Ibrahim, A. M., Forsido, S. F. and Kuyu, C. G. (2019). Effect of beeswax and chitosan treatments on quality and shelf life of selected mango (Mangifera indica L.) cultivars. Heliyon 5(1): 1-22.

Foo, S.Y., Nur Hanani, Z.A., Rozzamri, A. and IsmailFitry, M.R. (2019). Effect of chitosan-beeswax edible coatings on the shelf life of sapodilla (Achras zapota). Fruit. Journal of Packaging Technology and Research 3: 27-34.

Gerefa, S., Satheesh, N. and Berecha, G. (2015). Effect of essential oils treatment on anthracnose (Colletotrichum gloeosporioides) disease development, quality and shelf life of mango fruits (Mangifera indica L). AmericanEurasian Journal of Agricultural \& Environmental Science 15(11): 2160-2169.

Gomez, M.S., Cardoso, M.G.C., Guimaracs, A.C.G., Guerreiro, A.C., Gago, C.M.L. Boas, E.V.B.V., Dias, C.M.V., Manhita, A.C.C., Faleiro, M.L., Miguel, M.G.C. and Antunes, M.D.C. (2016). Effect of edible coatings with essential oils on the quality of red raspberries over shelf-life. Science of Food and Agriculture 97(3): 929938.

Harill, R. (1998). Using a refractometer to test the quality of fruits and vegetables. ( $2^{\text {nd }}$ ed.). Keedys Villle, Madagascar: Pink Noll Publishing

Islam, K., Khan, M.Z.H., Sarkar, M.A.R, Yeasmin, S., Ali, K. and Uddin, M.H. (2013). Postharvest quality of mango (Mangifera indica L) fruit affected by different levels of gibberellic acid during storage. Malaysian Journal of Analytical Sciences 17(3): 499 -509.

Juliani, H.R. and Simon, J.E. (2002). Antioxidant activity of basil. Trends in new crops and new uses. In: J. Janick and A. Whipkey (Eds.). ASHS Press, Alexandria, VA. 575-579.

Kodituwakku, T.D., Abeywickrama, K. and K. O. L. C. Karunanayake (2020). Pathogenicity of stem-end Rot associated fungi Isolated from "Karuthakolomban" mango and their control by spray and fumigation treatments with selected essential oils. The Journal of Agricultural Sciences - Sri Lanka 15(1): 19-36. 36http:// doi.org/10.4038/jas.v15i1.8669

Karunanayake, K. O. L. C., Sinniah, G.D., Adikaram, 
N.K.B. and Abayasekara, C. (2013). Cultivar differences in antifungal activity and the resistance to postharvest anthracnose and stem-end rot in mango (Mangifera indica L.). Australasian Plant Pathology 43: 151-159.

Kulasinghe, A.A. (2016). Use of selected essential oils as postharvest fungicides in mango fruit: for the control of stem-end rot disease of cv. Karuthacolomban and in vitro screening for the control of anthracnose disease of cv. Willard. Final year research project dissertation. OUSL.

Kulasinghe, A.A., Karunanayake, K.O.L.C. and Somaratne, S. (2019). Use of selected essential oils for controlling stem-end rot disease in mango (cv. Karuthacolomban). OUSL Journal 14(2): 75-90.

Larmond, E. (1977). Laboratory methods for sensory Evaluation of food, Canada Department of Agriculture.

Mladenoska, I (2012). The potential application of novel beeswax edible coatings containing coconut oil in the minimal processing of fruits. Advanced Technologies 1(2): 26-34.

Samane, M. and Mohammad, H. (2012). Effect of essential oils on postharvest decay and some quality factors of peach (Prunus persica) var. Redhaven Journal of Biological Environmental Science 6: 147-153.

Sefu, G., Satheesh, N. and Berecha, G. (2015). Effect of essential oils treatment on anthracnose (Colletotrichum gloeosporioides) disease development, quality and shelf life of mango fruits (Mangifera indica L). AmericanEurasian Journal of Agriculture and Environmental Science 15(11): 2160-2169.

Sokovic, M. and Griensven, L.J.L.D.V. (2006). Antimicrobial activity of essential oils and their components against the three major pathogens of the cultivated button mushroom, Agaricus bisporus. European Journal of Plant Pathology 116: 211-224.

Tripathi, P. and Dubey, N.K. (2004). Exploitation of natural products as an alternative strategy to control postharvest fungal rotting of fruit and vegetables. Postharvest Biology and Technology 32(3): 235-245

Tulloch, A.P. (1980). Beeswax-Composition and Analysis. Bee World 61(2):47-62 DOI: 10.1080/0005772X.1980.11097776

Tulloch, A.P., Hoffman, L.L. (1972). Canadian beeswax: Analytical values and composition of hydrocarbons, free acids and long chain esters. Journal of American Oil Chemical Society 49: 696-699.

Umuhozariho, M.G., Shayo, N.B., Sallah, P.Y.K. and Msuya, J.M. (2013). Sensory evaluation of different preparations of cassava leaves from three species as a leafy vegetable. African Journal of Biotechnology 13(46): 6452-6459.

Velickova, E., Winkelhausen, E., Kuzmanova, S., Alves, V.D. and Moldão-Martins, M. (2013). Impact of chitosan-beeswax edible coatings on the quality of fresh strawberries (Fragaria ananassa cv Camarosa) under commercial storage conditions. Food Science and Technology 52(2): 80-92.

Yimtoe, S., Barrett, D.M., Jangchud, K., Dhamvithee, P. and Jangchud, A. (2014). Effect of beeswax coating with Cinnamon oil on quality of sweet peppers. Kasetsart Journal (Natural Science) 48: 451 - 462. 